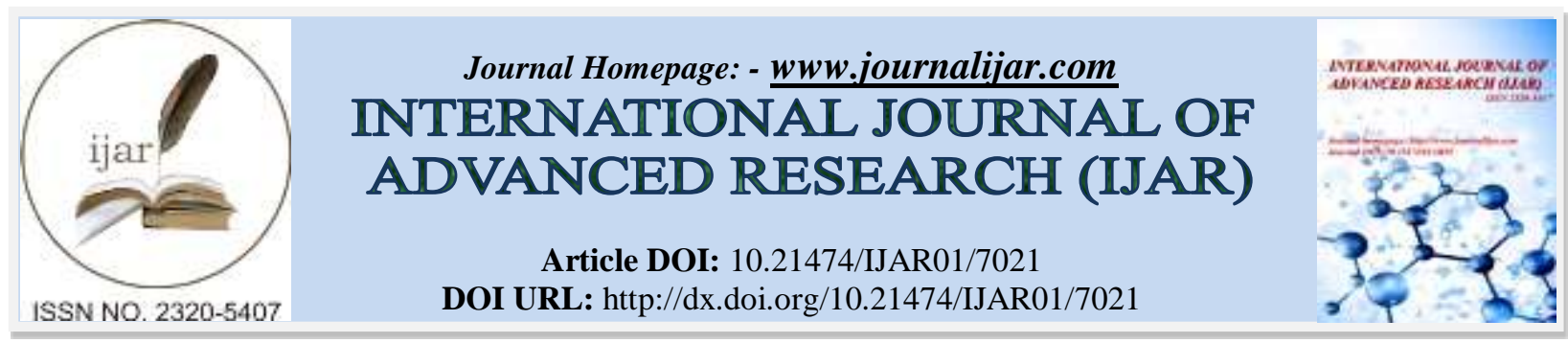

RESEARCH ARTICLE

\title{
A MULTI-SITE CASE STUDY: ALGEBRAIC CONTENT AND PEDAGOGICAL KNOWLEDGE OF SIXTH GRADE MATHEMATICS TEACHERS.
}

Dr. Mariyam Shahuneeza Naseer.

Walden University, USA.

\section{Manuscript Info}

Manuscript History

Received: 02 March 2018

Final Accepted: 04 April 2018

Published: May 2018

Keywords:-

algebra, teachers' content knowledge, teachers' pedagogical knowledge.

\section{Abstract}

Algebra is a fundamental topic in mathematics and lays the foundation for mathematical reasoning and complex problem-solving. A baseline study conducted in the Maldives showed that algebra test scores were the lowest compared to any other area of mathematics. Research shows that strengthening algebra instruction could improve student achievement. This concurrent mixed methods study examined the algebraic content and pedagogical knowledge of five sixth grade mathematics teachers who teach in five different schools across the Maldives. This study is guided by Shulman's major categories of teacher knowledge and Ball, Thames, and Phelps' domains of mathematical knowledge for teaching. The research questions examined the relationship between teachers' perceptions of their mastery of algebraic content and pedagogical knowledge, and what teachers actually know about algebraic content and pedagogy. Purposive sampling was used to select the 5 participants. Quantitative data were collected using the Diagnostic Teacher Assessments of Mathematics and Science - Middle Mathematics Teacher Assessments and qualitative data were gathered through lesson observations, interviews, and analysis of teachers' lesson plans and notes. All participants believed that they were proficient in both algebraic content and pedagogical knowledge. However, the results of this study showed that all participants lacked both algebraic content and pedagogical knowledge. Moreover, in-depth analysis of the textbooks and resource materials used by these teachers revealed that algebraic concepts were explained incorrectly in the prescribed textbooks, and resource materials.

Copy Right, IJAR, 2018. All rights reserved.

\section{Introduction:-}

A teacher's ability to teach mathematics content is influenced by the mathematical content and pedagogical knowledge of the teacher (Piccolo, 2008; Strand \& Mills, 2014). Shulman (1987) discussed categories of teacher knowledge that included content knowledge and pedagogical knowledge. In 2008, Ball, Thames, and Phelps (2008) refined Shulman's major categories of teacher knowledge and developed a model called domains of mathematical knowledge for teaching, which included mathematical content knowledge and pedagogical knowledge. Content knowledge was defined as the subject matter knowledge whereas pedagogical knowledge referred to the unique knowledge required to teach the subject-specific content (Ball, Thames, \& Phelps, 2008; Shulman, 1987). 
Mathematical content and pedagogical knowledge of teachers had been associated with students' ability and performance in subjects including algebra (El Mouhayar \& Jurdak, 2013; Strand \& Mills, 2014; Tajudin, 2014; Tennant \& Colloff, 2014). Algebra is a fundamental topic in mathematics that serves as a gateway to student skills necessary for mathematical reasoning and complex problem-solving (Cheng-Yao, Yi-Yin, \& Yu-Chun, 2014; Strand \& Mills, 2014). Research indicated that algebra is a topic students find difficult.

The problem examined in this study is the algebraic content and pedagogical knowledge of sixth grade mathematics teachers. It is commonly assumed that teachers who have a deep understanding of the content and pedagogy foster better student performance as they will employ better instructional practices than teachers who lack an in-depth understanding of the content and pedagogy (Ball, Lubienski, \& Mewborn, 2001; Brown, Davis, \& Kulum, 2011; Darling-Hammond \& Sykes, 2003; Ojose, 2014; Shirvani, 2015). Brown et al. (2011) reported that students taught by teachers equipped with the ability and knowledge to teach mathematics effectively produced six times better results compared to the students taught by teachers who lacked the ability and knowledge to teach mathematics effectively. Though it is unclear whether it is content knowledge or pedagogical knowledge or both content and pedagogical knowledge that lead to better student performance, it is apparent from the literature that the ability to teach mathematics depends on the mathematical content and pedagogical knowledge of the teachers (Begle, 1979; Piccolo, 2008; Strand \& Mills, 2014).

The ability to teach mathematics content is influenced by the mathematical content and pedagogical knowledge of the teachers (Piccolo, 2008). Teachers who lack a deep understanding of mathematics fail to teach students to develop conceptual understanding (Ma, 1999; Stoddart, Connell, Stofflett, \& Peck, 1993). Conceptual understanding is important as students who lack conceptual understanding tend to forget how to apply the concepts. Moreover, attaining new knowledge becomes challenging to those students (Welder, 2012). Conceptual understanding has been linked with the ability of the teacher to explain certain concepts. For example, Tajudin (2014) stated that lack of conceptual understanding in algebra could be the result of the way students were taught algebra. Often teachers who lack algebraic content knowledge emphasized computational procedures, which led students to make errors and develop misconceptions with regard to the concept of variables, algebraic expressions, algebraic equations, and word problems (Ball et al., 2001; Koency \& Swanson, 2000; Tajudin, 2014). Tennant and Colloff (2014) linked students' misconceptions to the approach teachers used in introducing and explaining algebraic concepts and simplifying algebraic processes. El Mouhayar and Jurdak (2013) reported that middle school students had difficulties in the areas in which teachers had difficulties. This is parallel to the findings of Shirvani (2015), who reported that teachers' knowledge affected students' performance on mathematics assessments. Shulman (1987) stated that the "teacher has special responsibilities in relation to content knowledge, serving as the primary source of student understanding of subject matter" (p. 9). This is parallel to the findings of Ojose (2014) that indicated teachers' knowledge of mathematical content significantly affected the way concepts were taught and specifically pointed out that teachers who lacked mathematical content knowledge tended to assume that students knew and understood the concepts. This limited the mathematical content to which students were exposed (Ojose, 2014; Strand \& Mills, 2014).

\section{Purpose of the Study and Research Question:-}

It is evident from professional literature that mathematical content and pedagogical knowledge of teachers play a crucial role in teaching mathematical concepts in a way that helps students develop conceptual understanding of the subject matter. Moreover, it is believed that highly qualified teachers of mathematics lead to better student performance although it is unclear exactly what types of knowledge contribute to these performance gains (Ball et al., 2001; Begle, 1979; Brown et al., 2011; Darling-Hammond \& Sykes, 2003; Ojose, 2014; Shirvani, 2015).

A baseline study conducted in the Maldives between 2012 and 2013 indicated students scored the lowest in algebra compared to any other topics in mathematics (United Nations Children's Fund \& National Institute of Education [UNICEF \& NIE], 2014). The study reported that students lacked conceptual understanding of algebra. An interview with a local researcher who served as the local project manager of this baseline study indicated the importance of studying the algebraic content and pedagogical knowledge of the in-service teachers because it was thought to be linked to student performance (A. Shareef, personal communication, April 22, 2015). For all these reasons, it is significant to find out the algebraic content and pedagogical knowledge strengths and weaknesses of mathematics teachers in the Maldives in order to determine the focus of professional development curriculum of in-service teachers. 
Hence, the purpose of this study is to examine the algebraic content and pedagogical knowledge of the sixth grade mathematics teachers in the Maldives, specifically by answering the following main research questions:

1. What is the relationship between teachers' perceptions of their mastery of algebraic content and pedagogical knowledge, and what teachers know about algebraic content and pedagogy as measured by Diagnostic Teacher Assessments in Mathematics and Science - Middle Mathematics Teacher Assessments (DTAMS)?

2. As measured by DTAMS, what are the specific algebraic content and pedagogical knowledge strengths and weaknesses of sixth grade mathematics teachers?

\section{Review of the Literature:-}

The capability to teach mathematics content is greatly influenced by mathematical content and pedagogical knowledge of the teacher (Piccolo, 2008; Strand \& Mills, 2014). Several studies have been conducted to understand teachers' mathematical content and/or pedagogical knowledge since Shulman $(1986,1987)$ put forward the idea of categories of required knowledge for teaching, upon which Ball et al. (2008) developed the domains of mathematical knowledge required for teaching (Browning et al., 2014; Buschang et al., 2012; Hauk, Toney, Jackson, Nair, \& Tsay, 2014; Hill, Ball, \& Schilling, 2008; Jing-Jing, 2014; Kleickmann et al., 2015; Lange, Kleickmann, \& Moller, 2012; Liu, 2010; Shirvani, 2015; Thanheiser et al., 2014).

It is widely believed that students taught by teachers who have a strong mathematical content and pedagogical knowledge perform better in mathematics compared to those who are taught by teachers who lack an in-depth understanding of mathematical content and pedagogical knowledge (Ball et al., 2001; Begle, 1979; Brown et al., 2011; Darling-Hammond \& Sykes, 2003; Ojose, 2014; Shirvani, 2015; Strand \& Mills, 2014). Teachers who lack content knowledge found it difficult to explain concepts to the students and made mathematical errors in the classroom while teaching (Shirvani, 2015). Ojose (2014) reported that teachers who had the content knowledge but lacked pedagogy offered "skeletal explanations loaded with routines" (p. 41), while Tajudin (2014) reported that teachers who lacked content knowledge focused on procedures. This resulted in students being offered mathematically incorrect answers when they sought understanding by asking questions (Ojose, 2014). These clearly indicate that in order to teach mathematics well teachers are not only expected to have a commanding knowledge of the content they teach but they also need to know the right approach that could be used to teach the specific content for the target audience (Ojose, 2014; Shirvani, 2015; Strand \& Mills, 2014).

During 2012 and 2013 a baseline survey was conducted in the Maldives, and the results indicated that students performed poorest in algebra compared to any other area in mathematics (UNICEF \& NIE, 2014). Interviews with researchers, teacher educators, and heads of schools revealed that they all believed the poor performance of students in algebra was the result of deficient algebraic content and pedagogical knowledge of the mathematics teachers (A. Gasim, personal communication, April 23, 2015; A. Shareef, personal communication, April 22, 2015; A. Waheed, personal communication, March 7, 2015; M. Qasim, personal communication, April 13, 2015). The algebraic content and pedagogical knowledge of mathematics teachers in the Maldives have never been studied. Therefore, this study is important, as this study would confirm or contradict the belief that the poor performance of students in algebra was the result of a deficiency in the algebraic content and pedagogical knowledge of mathematics teachers.

\section{Theoretical Frameworks:-}

This study is guided by two theoretical frameworks, namely, Shulman's major categories of teacher knowledge (1987) and the domains of mathematical knowledge for teaching proposed by Ball, Thames, and Phelps (2008). Lee Shulman outlined the categories of knowledge required by a teacher to teach, and for the first time pedagogical content knowledge was mentioned in education. Ball et al. developed Shulman's idea of pedagogical content knowledge and linked that to content knowledge. In addition, Ball et al. developed a model that focused specifically on the knowledge required to teach mathematics.

Shulman's major categories of teacher knowledge. The first is the Shulman's major categories of teacher knowledge. In 1987 Shulman outlined seven categories of teacher knowledge required for a teacher to teach. According to Shulman $(1987$, p. 8$)$ they are:

1. Content knowledge;

2. General pedagogical knowledge, with special reference to those broad principles and strategies of classroom management and organization that appear to transcend subject matter;

3. Curriculum knowledge, with particular grasp of the materials and programs that serve as "tools of the trade" for teachers; 
4. Pedagogical content knowledge, that special amalgam of content and pedagogy that is uniquely the province of teachers, their own special form of professional understanding;

5. Knowledge of learners and their characteristics;

6. Knowledge of educational contexts, ranging from the workings of the group or classroom, the governance and financing of school districts, to the character of communities and cultures; and

7. Knowledge of educational ends, purposes, and values, and their philosophical and historical grounds.

Shulman's definition of content knowledge was not just limited to the knowledge of concepts, theories, ideas, and proofs but also covered the approaches to develop this knowledge (Fernandez, 2014). Shulman (1986) argued that in order to teach a subject it is crucial that teachers knew more than just the facts and concepts. He believed that teachers knowing that something is so is not enough. In addition teachers should understand the why something is so. Shirvani (2015) reported that teachers who had a strong content knowledge were capable of implementing more flexible teaching strategies that helped students better understand more complex mathematical concepts. This is parallel to the findings of Strand and Mills (2014) who reported that in order to tailor instruction in a way that develops students' understanding, it is important that teachers have a strong understanding of the algebraic content related pedagogy.

Shulman's second category, general pedagogical knowledge, included "educational purposes and values and, in addition requires a cognitive, social and developmental theory of learning and how they apply within the classroom" (Fernandez, 2014, p. 83). Shulman (1986) defined curricular knowledge as "the full range of programs designed for the teaching of particular subjects and topics at a given level, the variety of instructional materials available in relation to those programs, and the set of characteristics that serve as both the indications and contraindications for the use of particular curriculum or program materials in particular circumstances" (p. 10).

Shulman further subdivided curricular knowledge into lateral curriculum knowledge and vertical curriculum knowledge (Ball et al., 2008). Lateral curriculum knowledge is the knowledge of how the curriculum relates to the curriculum that is taught to students in other classes while vertical curriculum knowledge is used to represent the knowledge of curriculum that is taught to students across the grades in the same subject area (Ball et al., 2008).

In 1986 Shulman introduced and in 1987 developed the idea of pedagogical content knowledge for the first time (Ball et al., 2008; Fernandez, 2014). This was a departure from what was focused in education research those days (Ball et al, 2008). Shulman referred to this as the missing paradigm in research on teaching and teacher knowledge (Fernandez, 2014). Shulman (1986) described pedagogical content knowledge as the knowledge of subject matter knowledge required for teaching. He went on to explain that pedagogical content knowledge also includes understanding of what makes learning of certain concepts easy or difficult. In addition, he explained that pedagogical content knowledge covers the preconceptions and misconceptions associated with learning of specific concepts according to age and the background of the students. In particular, knowing the strategies that could be used to address those shortcomings and reorganize the understanding of the students come under pedagogical content knowledge. The last three categories addressed the general dimensions of teacher knowledge that were the backbone of teacher education programs of that time, hence, were not the main focus of Shulman's work (Ball et al., 2008).

Domains of mathematical knowledge for teaching. The second theoretical framework that guided this study is the domains of mathematical knowledge for teaching proposed by Ball, Thames, and Phelps (2008). The domains of mathematical knowledge for teaching was built on Shulman's theoretical framework connecting content knowledge to practice of teaching (Ball et al., 2008). According to Ball et al. (2008), in 1986 Lee Shulman and colleagues put forward a domain of teacher knowledge which linked content knowledge and teaching, and they called it pedagogical content knowledge. Since then, this domain has gained the popularity and Shulman's idea has been cited in more than 1,200 refereed journal articles in 125 different journals in "professions ranging from law to nursing to business, and regarding knowledge for teaching students preschool through doctoral studies" (Ball et al., 2008, p. 392).

Ball et al. (2008) refined Shulman's categories and proposed the model in Figure 1. Figure 1 shows the domains of mathematical knowledge for teaching. This has been cited 4,222 times since then. 


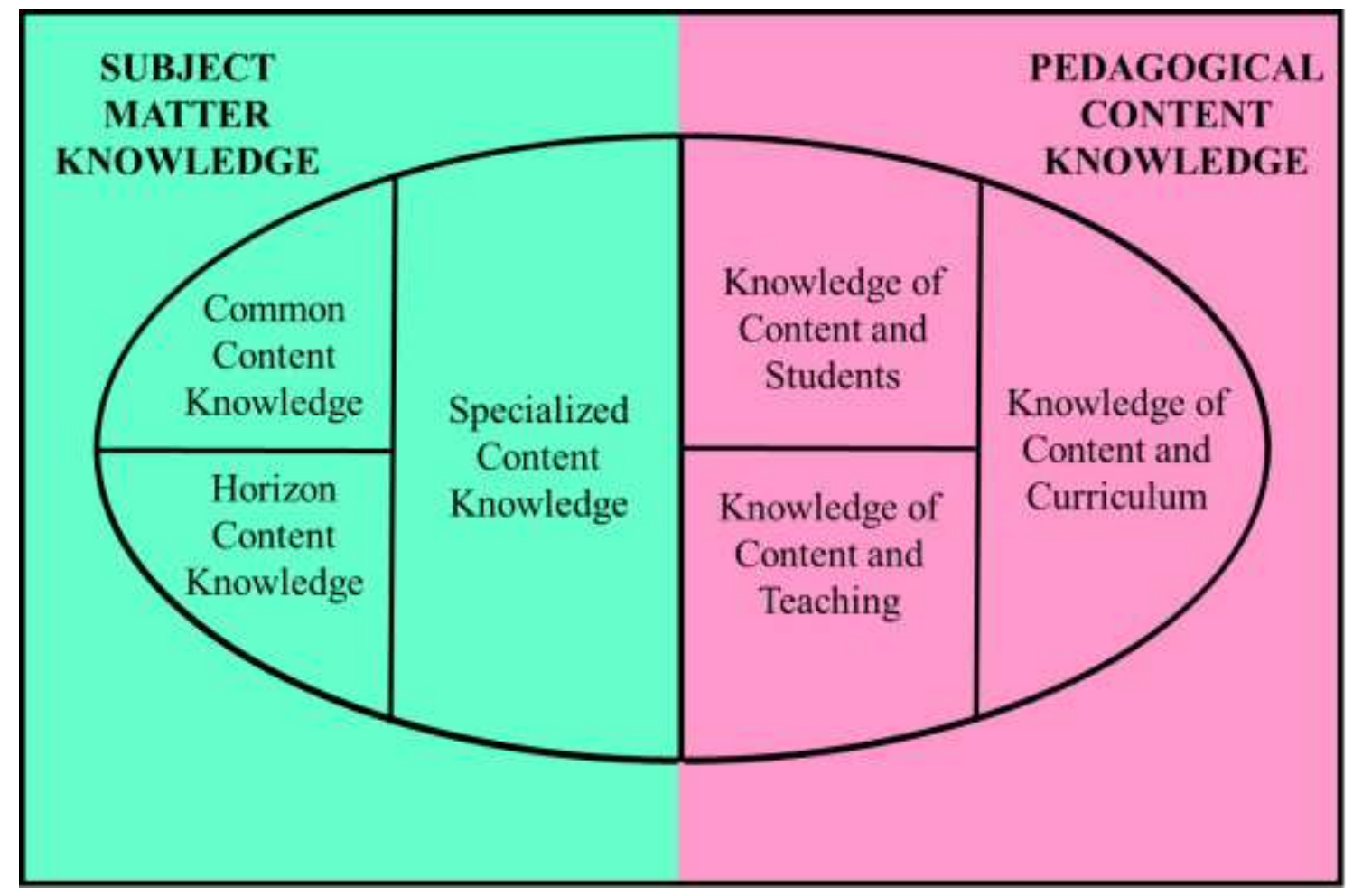

Figure 1:- Domains of mathematical knowledge for teaching (Ball et al., 2008).

Ball et al. (2008) proposed six domains, namely, common content knowledge; horizon content knowledge; specialized content knowledge; knowledge of content and students; knowledge of content and teaching; and knowledge of content and curriculum (as shown in Figure 1). These six domains come under two main categories subject matter knowledge and pedagogical content knowledge.

Subject matter knowledge. Subject matter knowledge is the subject specific knowledge of content. This category is subdivided into common content knowledge, horizon content knowledge, and specialized content knowledge.

Common content knowledge. Common content knowledge is defined as "the mathematical knowledge and skill used in settings other than teaching" (Ball et al., 2008, p. 399). This includes knowing the materials they teach; being able to identify incorrect answers given by students; recognizing inaccurate definitions presented in textbooks; and being able to use terms and notations correctly. In short, common content knowledge is defined as "the mathematical knowledge known in common with others who know and use mathematics" (Ball et al., 2008, p. 403). Some research indicated that teachers' high school mathematics knowledge is positively correlated with students' learning gains (Shirvani, 2015).

Horizon content knowledge. Horizon content knowledge is defined as the awareness of how mathematical topics are related over the span of mathematics included in the curriculum (Ball et al., 2008, p. 403). For example, primary teachers may need to know how categorization of shapes and pattern generalizations can set the mathematical foundation for formal algebra, which is taught in sixth grade in the Maldives.

Specialized content knowledge. Specialized content knowledge is defined as "the mathematical knowledge and skill unique to teaching" (Ball et al., 2008, p. 400). An example of this could be the analysis of a student's incorrect answer to find out the nature of the error because, this would require dexterity in thinking about numbers, being aware of the patterns, and being able to critically examine the meaning in ways that are unique to teaching (Ball et al., 2008).

Pedagogical content knowledge. Ball et al. (2008) cited Shulman's definition of pedagogical content knowledge as follows: 
The most useful forms of representation of those ideas, the most powerful analogies, illustrations, examples, explanations, and demonstrations - in a word, the most useful ways of representing and formulating the subject that make it comprehensible to others. Pedagogical content knowledge also includes an understanding of what makes the learning of specific topics easy or difficult: the conceptions and preconceptions that students of different ages and backgrounds bring with them to the learning of those most frequently taught topics and lessons. (p. 391-392)

Magnusson, Krajcik, and Borko (as cited in Ball et al., 2008) defined pedagogical content knowledge as a teacher's understanding of how to help students understand specific subject matter. It includes knowledge of how particular subject matter topics, problems, and issues can be organized, represented and adapted to the diverse interests and abilities of learners, and then presented for instruction. The defining feature of pedagogical content knowledge is its conceptualization as the result of a transformation of knowledge from other domains (p. 394).

In summary it can be said that pedagogical content knowledge is the unique knowledge required to teach subjectspecific content. Ball et al. (2008) subdivided the pedagogical content knowledge into three domains. These domains are knowledge of content and students; knowledge of content and teaching; and knowledge of content and curriculum. Pedagogical knowledge of the teacher is important as teachers who have content knowledge but lack pedagogical knowledge not only find it difficult to explain mathematical concepts to the students in a way that they would understand but also are likely to make errors in classroom teaching (Ojose, 2014).

Knowledge of content and students. Knowledge of content and students is defined as the "knowledge that combines knowing about students and knowing about mathematics" (Ball et al., 2008, p. 401). This means teachers should be able to recognize how the students would think when presented with a certain problem and also teachers should be able to judge what the students would find confusing with the presented problem. In addition, teachers not only should be able to predict what kind of examples would make it easier for the students to grasp the concept but also what type of examples would maintain or build their interest in the lesson presented.

Knowledge of content and teaching. Ball et al. (2008) defined knowledge of content and teaching as "knowing about teaching and knowing about mathematics" (p. 401). In other words, teachers should be able to identify which instructional strategies would suit a certain lesson and also the sequence of the lesson, for instance, teachers being able to recognize which example would work best in the beginning or the introduction phase of the lesson.

Knowledge of content and curriculum. Ball et al. (2008) cited Shulman's definition of curricular knowledge instead of proposing a definition. Shulman defined curricula knowledge as [knowledge] represented by the full range of programs designed for the teaching of particular subjects and topics at a given level, the variety of instructional materials available in relation to those programs, and the set of characteristics that serve as both the indications and contraindications for the use of particular curriculum or program materials in particular circumstances (as cited in Ball et al., 2008, p. 391).

Ball et al. (2008) developed the framework domains of mathematical knowledge for teaching after analyzing existing literature on knowledge base for teaching. This specifically focused on mathematics teaching and had identified the necessary aspects of mathematics knowledge for teaching. Moreover, this framework had been cited 4,222 times since then. No obvious blind spots to use of this framework in examining mathematical content knowledge and pedagogical knowledge have been identified. Remarkably, during the course of this study, no blind spots to use of this framework were uncovered.

\section{Research Methodology:-}

As the purpose of this study was to examine the algebraic content and pedagogical knowledge of sixth grade mathematics teachers in the Maldives, a mixed-methods collective case study design was the most appropriate in which the "bounded system" refers to the sixth grade algebra teachers. In mathematics education research, qualitative and quantitative data have been used to complement one another and to more thoroughly understand the relationships between observation and assessment data (Ross \& Onwuegbuzie, 2012). As this study sought to gain an in-depth understanding of algebraic content and pedagogical knowledge of sixth grade mathematics teachers in the Maldives, a mixed methods design was believed to be the most appropriate design for this study.

Quantitative data were collected using DTAMS. The instrument was used to establish the baseline algebraic content and the pedagogical knowledge of the sixth grade mathematics teachers. It was developed by teams of 
mathematicians, mathematics educators, and middle-school teachers to measure the content knowledge and pedagogical knowledge of middle-school teachers (DTAMS, n.d.; Saderholm et al., 2010). The coverage of the algebraic content was determined by reviewing a wide range of literature regarding what algebraic concepts middleschool students and teachers should know. Three types of reliability, internal reliability, equivalency reliability, and inter-scorer reliability, were established and it was reported that the reliability score for each of these forms was greater than 0.8, which is considered acceptable for research purposes (DTAMS, n.d.; Saderholm et al., 2010). Content validity of the assessment was established by aligning the assessment design to United States recommendations, objectives of standardized assessments, and research on misconceptions of students and teachers of middle school (DTAMS, n.d.; Saderholm et al., 2010). Content validity of DTAMS to use in the Maldives was established by checking alignment of the assessment tasks against the learning outcomes of the National Primary Mathematics Curriculum and the learning outcomes of the mathematics content and pedagogy courses offered to primary teachers at teacher training institutions in the Maldives. Construct validity of DTAMS was established by eight national reviewers including mathematics educators and mathematics lecturers. Five of the eight reviewers were employed at teacher training institutions in the Maldives at the time of this study, while the other three reviewers had worked in various positions at teacher training institutions, particularly in the mathematics department, before moving on to higher positions in academia. Two of the reviewers were initially trained as primary teachers and had taught sixth grade mathematics. These eight reviewers checked the appropriateness of assessment tasks for the teachers teaching sixth grade mathematics in the Maldives.

Qualitative data were collected through observations of sixth grade algebra lessons, interviews with sixth grade mathematics teachers, and analyses of teacher's algebra lesson plans and lesson notes. In order to develop an indepth understanding of the algebraic content and pedagogical knowledge of the sixth grade mathematics teachers multiple forms of data need to be collected (Caruth, 2013; Creswell, 2012). For instance, Ball et al. conducted an extensive qualitative analysis of teaching practice to study the mathematical knowledge for teaching (Ball et al., 2008). Central to the qualitative approach used by Ball et al. was the analysis of videotaped and audiotaped classroom lessons, transcripts, copies of students' written classwork, homework, and quizzes, along with teacher's lesson plans, notes, and reflections (Ball et al., 2008).

\section{Population and Sampling:-}

As this study aimed to examine the algebraic content and pedagogical knowledge of sixth grade mathematics teachers in the Maldives, the sampling strategy used for this study was homogeneous, purposive sampling. Due to high level of homogeneity among the participants, saturation was achieved after three interviews, however, data were collected from all five subjects who consented to take part in the study.

As the purpose of this study was to understand the algebraic content and pedagogical knowledge of the sixth grade mathematics teachers in the Maldives, all sixth grade mathematics teachers are eligible to take part in the study. In order to select the participants, initially all sixth grade mathematics teachers employed in the selected 14 schools were contacted. The teachers were given the consent form that included a detailed description of the study. Of the 14 teachers who were approached only seven consented to participate in the study. The seven teachers who consented to take part in the study were provided with the data collection coordination request and confidentiality agreement. During the interview, one of the participants withdrew while a second participant decided to drop out after the second observation. Therefore, five participants continued till the end of the study. As all Maldivian sixth grade mathematics teachers were trained from the same institution, and all the participants were recruited from public schools, a high level of homogeneity among the population was observed.

\section{Data Collection Strategies:-}

Data were collected concurrently. Qualitative data were collected through analysis of algebra lesson plans and lesson notes, observations of algebra lessons, and sixth grade mathematics teacher interviews. Observations of algebra lessons provided the researcher with a better understanding as to how algebraic concepts were explained to the students at sixth grade which is influenced by the teachers' algebraic content and pedagogical knowledge (Piccolo, 2008). As a result, this provided the researcher with information with regard to the algebraic content and pedagogical knowledge of sixth grade mathematics teachers in the Maldives. The quantitative data collection instrument used in this study was DTAMS. This was used to establish the baseline algebraic content and pedagogical knowledge of the sixth grade mathematics teachers in the Maldives. At the end of the initial interview, each interviewee was asked to complete the DTAMS. The reason for administering DTAMS right after the interview was to avoid any bias that could arise if there was a lapse between interview and administering of DTAMS. For 
example, after the interview, participants could study algebraic content and learn about the pedagogy before they completed DTAMS.

\section{Findings:-}

Qualitative data were collected through observations, interviews, and analysis of documents while quantitative data were collected using DTAMS. Qualitative data were used to gain an in-depth understanding of the algebraic content and pedagogical knowledge while quantitative data were used to establish the baseline algebraic content and the pedagogical knowledge of the sixth grade mathematics teachers. Data collected through observations of sixth grade algebra lessons, interviews with sixth grade mathematics teachers, and teachers' algebra lesson plans and lesson notes were reviewed and analyzed for themes and patterns such as content knowledge, pedagogical knowledge, and any other sub-categories which might emerge from the data. Data collected using DTAMS were sent to the Center for Research in Mathematics and Science Teacher Development (CRMSTD) staff for a detailed analysis of the algebraic content and pedagogical knowledge of the five sixth grade teachers that participated in the study. The analysis was comprised of a summary of each teacher's performance that included scores on individual items, on each mathematics subdomain in algebra, and on algebraic content knowledge and pedagogical knowledge. Content knowledge was further analyzed for memorized knowledge, conceptual understanding, and higher-order thinking and problem-solving, all of which comes under common content knowledge in Ball's framework (Ball et al., 2008). Pedagogical knowledge covered the most useful form of representation of algebraic ideas; the most powerful analogies, illustrations, examples, explanations and demonstrations; and identification of student misconceptions and providing strategies to correct them that promote understanding, reasoning and proficiency. All of these come under knowledge of content and students, and knowledge of content and teaching in Ball's framework (Ball et al., 2008). This analysis of performance on specific items, subdomain topics, and knowledge levels allowed for an indepth understanding of teacher's algebraic content and pedagogical knowledge of sixth grade mathematics teachers in the Maldives.

\section{Personal Information of the Participants:-}

Table 1 summarizes the personal information of the participants with regard to years of experience in teaching sixth grade mathematics, highest qualification achieved and major, number of mathematics content courses taken in college, number of mathematics pedagogy courses taken in college, and the number of professional development sessions on mathematics.

Table 1:-Personal Information

\begin{tabular}{|l|l|l|l|l|l|}
\hline ID & MSN001 & MSN002 & MSN003 & MSN005 & MSN006 \\
\hline Years of Experience & 13 & 7 & 20 & 2 & 18 \\
\hline Highest Qualification & B. Ed. $^{1}$ & Dip. $^{2}$ & Adv. Dip. $^{3}$ & B. Ed. & B. Ed. \\
\hline Major & $\begin{array}{l}\text { Secondary } \\
\text { Math }\end{array}$ & Dhivehi $^{4}$ & Math & $\begin{array}{l}\text { Secondary } \\
\text { Math }\end{array}$ & Primary \\
\hline Number of Content Courses & 7 & None & 2 & 6 & 2 \\
\hline Number of Pedagogy Courses & 2 & None & None & None & 2 \\
\hline $\begin{array}{l}\text { Number of Professional Development } \\
\text { Sessions on Mathematics }\end{array}$ & None & None & None & None & None \\
\hline
\end{tabular}

${ }^{1}$ Bachelor of Education, ${ }^{2}$ Diploma in Teaching, ${ }^{3}$ Advanced Diploma in Teaching, ${ }^{4}$ Dhivehi is the native language of the Maldivians, ${ }^{5}$ All the subjects taught in Primary with the exception of Dhivehi, Islam, and Quran.

\section{Lesson Observation:-}

A total of 80 lessons were observed at five different sites over a 10 week period. All the five teachers introduced algebra using what Tennant and Colloff (2014) referred to as 'fruit salad' approach to algebra. Two of the five teachers actually used fruits while one used fruits and vegetables, one used stationery (that is, books and pens), and the remaining teacher used front and the back of the teacher's hands to demonstrate like and unlike terms. This clearly indicated that the teachers lacked the common content knowledge as they were unaware that the "letters" or "variables" used in algebra represented numbers, not objects. Ball et al. (2008) placed common content knowledge as a subdivision of subject matter knowledge (content knowledge) and defined it as knowledge of mathematics that is common to everyone who knew and used mathematics.

None of the teachers related the lesson to real-life (however, during the interviews it became clear that teachers believed by using stationery or using fruits and vegetables they had related the lesson to real-life). Also, it was 
observed that none of the teachers identified or even mentioned common errors or potential misconceptions students might have (in fact, teachers ignored the incorrect answers given by students and hurried to write the correct answers given by students on the board). It was also observed that none of the teachers used a different approach to explain to the students who did not understand the lesson. Either the same example was repeatedly explained or (as in most cases) another student was asked to help the student who did not understand the lesson. It was observed that teachers were unable to differentiate instruction to cater the needs of the students. Differentiated instruction had shown improvements in students' performance (Rittle-Johnson, Matthews, Taylor, \& McEldoon, 2011). Teachers gave questions to try as to keep the students engaged and it was observed that teachers encouraged individual students to answer by calling out their names (later on it became clear that teachers invited the same crowd to answer questions and students who had questions were always referred to these students). In short, it became clear that teachers lacked pedagogical knowledge required to teach algebra. It is noteworthy that teachers' lack of algebraic content and pedagogical knowledge could lead students to develop misconceptions with regard to the concept of variables, making it difficult for students to understand problems involving algebraic expressions or equations (Ball et al., 2001; Koency \& Swanson, 2000; Tajudin, 2014).

Teachers had sufficient knowledge to demonstrate how to do the calculations and they were confident in showing examples. Through the observation it was clear that teachers were able to solve the problems correctly, however, it was difficult to conclude anything about their algebraic content knowledge. Tajudin (2014) reported that teachers who lacked content knowledge focused on procedures. Therefore, it could be possible that these teachers lacked algebraic content knowledge. It became clear that teachers were using one teaching strategy, that is, explain through the use of examples how to get the correct answer. Students' roles were to follow the steps in solving problems. It was clear that teachers promoted procedural fluency over conceptual understanding, critical-thinking, and creativity. From the teaching approach, it became clear that teachers lacked pedagogical knowledge. Teachers offered "skeletal explanations loaded with routines" (Ojose, 2014, p. 41). Moreover, it became apparent that examples discussed and exercise questions were the type of questions that will be asked in the examinations. Hence, making it clear that teachers were preparing students to obtain a good score [or at least make them all pass] in the examinations.

It was also observed that students were able to do the "cross multiplication" correctly when fractions were involved. However, they made mistakes in obtaining solutions. From two classes it was observed that the mistakes or misconceptions students had were almost the same. This could be the result of distorted explanations such as "sign changes when you move a number from one side to the other". Naseer (2015) and Schnepper and McCoy (2013) stated that the root cause of misconceptions were the result of incomplete or distorted definitions. It was clear from the explanations that teachers did not have sufficient knowledge to teach algebra at sixth grade. For instance, all five teachers said that 'when you move the number from one side to the other its sign change to opposite.' Teachers who lacked content knowledge focused on computational procedures (Ball et al., 2001; Koency \& Swanson, 2000; Tajudin, 2014). A person with sufficient knowledge would have stated that they are 'not moving' numbers but treating both sides equally either by dividing both sides by the same number or multiplying both sides by the same number to ensure the numbers statement (equation) is true. None of the teachers used different teaching strategies or promoted conceptual understating or creativity. Instead, teachers focused on computational procedures. Teachers did not identify or address potential errors and misconceptions. In fact, they failed to detect students' misconceptions raising serious questions about teachers having sufficient algebraic content and pedagogical knowledge to teach sixth grade algebra. Identifying students' misconceptions and correcting those is essential to advancing students' conceptual understandings (Russell, O’Dwyer, \& Miranda, 2009). From the observations of algebra lessons, it became clear that teachers not only lacked algebraic content knowledge but also pedagogical knowledge.

\section{Document Analysis:-}

Documents and written materials such as lesson plans and notes can provide rich information and evidence in qualitative studies. Pedagogical knowledge of teachers could be observed through teachers' lesson plans and lesson notes (Chick, 2006; Patton, 2002). Algebra lesson plans and lesson notes of the sixth grade mathematics teachers who consented to take part in this study were analyzed to gain an in-depth understanding of the algebraic content and pedagogical knowledge of the sixth grade mathematics teachers.

Only one of the five teachers had a lesson plan. Teachers used Mathematics for Maldivian Schools Six (Adam \& Naseer, 2002), Mathematics for Maldivian Schools Six Workbook (Adam \& Naseer, 2002), Mathematics for Maldivian Schools Six Teacher's Resource Book (Adam \& Naseer, 2003), and Mathematics in the National Curriculum Key Stage 2 (National Institute of Education (NIE), 2014) as lesson notes. 
Document analysis showed that the prescribed textbooks and other resource books prepared for the Maldivian Schools had focused on computational procedures rather than developing conceptual understanding, problemsolving skills, or analytical skills. It also became clear that teachers were following the textbook and resource materials sent to them word for word. However, in order to promote knowledge growth and conceptual understanding it is important that explicit attention is given to differentiated instruction and open discussions rather than simple textbook exposure (Rittle-Johnson et al., 2011). Moreover, in-depth analysis of the textbooks and resource materials used by these teachers revealed that algebraic concepts were explained incorrectly in the prescribed textbooks, and resource materials. Teachers not being able to detect these incorrect explanations provide evidence that these teachers lack common content knowledge as well as knowledge of content and teaching (Ball et al., 2008). Ball et al. placed common content knowledge as a sub-category of subject matter knowledge (which in this study is algebraic content knowledge) whereas knowledge of content and teaching was placed under pedagogical knowledge. In short, this confirmed that teachers lack algebraic content and pedagogical knowledge required to teach at sixth grade.

\section{Interviews:-}

Only one of the participants who taught mathematics at the sixth grade level had a language qualification whereas all others were qualified teachers either in teaching primary or teaching mathematics. It was discovered during the interview that the participant who had a language qualification was teaching mathematics at sixth grade because when the participant joined the school, there were no posts related to the participant's area of study. The participant was further asked what made the participant to agree to teach mathematics, the response was that "I can do all the questions in the grade six textbook without difficulty so I agreed to teach mathematics. Since then I have been teaching mathematics and so far I have had no complaints from students or their parents."

The variations in number of mathematics content and pedagogy courses for the same qualification from the same institution was due to the variations in time of graduation. It is also noticeable that three of the participants reported that they had not studied any mathematics pedagogy modules, however, they mentioned that they have studied general pedagogy modules in which they learned Bloom's taxonomy, questioning skills, and different approaches to teaching. During the interview it became clear that four of the participants had studied at least one algebra module in college. The participant who did not study any mathematics content or pedagogy modules was the one who qualified as a language teacher.

Interestingly, only one of the participants among the five was qualified to teach at primary level while three of the five participants were qualified to teach mathematics at secondary level. This clearly indicated that there was a mismatch in teachers' qualifications and their jobs, which should be further explored in order to identify the reasons for these mismatches and possible solutions to address this issue. Also, another important observation was that each of the teachers had been undertaking 15 hours of professional development per year (since 2009) as it was mandatory for public school teachers. However, none of them attended a mathematics professional development. The reason they cited was that schools focused on general topics such as using PowerPoint presentations, classroom management, and behavior management. One of the participants mentioned that the professional development day was a "waste of time" as it was more seen as a day to have fun at school without students around. All five participants agreed that the professional development did not contribute towards enhancement of their algebraic content knowledge or pedagogical knowledge as they never got the opportunity to attend a professional development session tailored for mathematics teachers. Taton (2015) argued for the importance of having subject-specific professional development and stated that most of the professional development available for teachers were not useful as they were more generic. All five participants stated that the current professional development practice was useless and expressed their interest to attend a mathematics professional development.

All five teachers stated that they were very confident in teaching sixth grade algebra and cited that they were able to do all the questions in the textbook as the reason for their confidence. One of the five teachers said that when a student gave an incorrect answer, the teacher asked a "good student" to explain the question to the student who obtained the incorrect answer. In this teacher's opinion, when a good student explained it became easier for the weak students to understand instead of the teacher explaining "the same thing repeatedly". The remaining four of the five teachers said that they explained the problem on the board or at times individually to the student. The lack of analysis of student mistakes indicated that the teachers lack what Ball et al. (2008) referred to as Specialized Content Knowledge that is a form of subject matter knowledge (which in this study is algebraic content knowledge). The 
teachers repeatedly offering the same explanation when a student asked a question indicated that they lack pedagogical content knowledge and specifically, Knowledge of Content and Students (Ball et al., 2008).

Four of the five teachers believed that students are first exposed to algebraic concepts when they are in grade six indicating that they lack Horizon Content Knowledge, which is the knowledge of how the curriculum is spread across the grades (Ball et al., 2008). The remaining teacher believed that although students are taught formal algebra in grade six, they encounter algebraic concepts in earlier grades. This teacher stated:

From primary onwards they are exposed to algebra. Because they are actually doing perimeter and area. There they have length into breadth. Which is $l$ into $b$. that is algebra. But formally as a topic we introduce in grade 6 . They are exposed to the concept before grade 6 .

All five teachers stated that they did not use any additional materials other than the prescribed textbooks and resources prepared for sixth grade. From the interview it also became clear that all teachers lacked pedagogical knowledge. For example, all the teachers cited use of fruits and vegetables or use of stationery to represent variables (which is incorrect) as relating the concept to real-life. Remarkably, all five teachers believed that the lesson they delivered was perfect and there was nothing they would change, if they were to re-teach the lesson again. They also believed that all the students understood the lesson because the students did not ask any questions. However, one of the teachers mentioned that students ask "silly questions" because they were not paying attention. The "silly question" student asked was "why not $5 a b$ ?" when the teacher explained that 3 apples and 2 bananas can be written as $3 a+2 b$. Categorizing this question as "silly" and considering students not asking questions as an indicator of learning suggested that this teacher lacked Specialized Content Knowledge, Knowledge of Content and Students, and Knowledge of Content and Teaching. These three types of knowledge are covered under subject matter knowledge or content knowledge, and pedagogical knowledge (Ball et al., 2008; Shulman, 1987).

Interestingly, teachers introduced algebra using the "fruit salad" approach because the teachers thought by using that approach they were relating algebra to real-life. Teachers identified sign mistakes as the only misconception students had. However, observations revealed that students had misconceptions due to incomplete or distorted explanations offered. For example, teachers said that "when you take a number to the other side, its sign changes to opposite" and this resulted in students incorrectly writing $7 x=21 \Rightarrow x=21-7$. It was also discovered that teachers were unable to detect misconceptions that indicated that they lacked not only algebraic content knowledge but also pedagogical knowledge (Ball et al., 2008; Shulman, 1987).

\section{DTAMS:-}

In-depth analysis of DTAMS showed that the highest score obtained was for memorized knowledge that was five out of a possible 10 points. This score was obtained by three of the five teachers, whereas the other two scored below five out of a possible 10 points. The highest score for conceptual understanding was also five out of a possible 10 points that was scored by only two out of five participants. Reasoning and problem-solving was the lowest scored domain among the five participants. The highest score obtained in the domain was three, while the lowest was a zero out of a possible 10 points. These scores indicated that teachers lacked sufficient algebraic content knowledge required to teach sixth grade algebra. 
Figure 2 shows a detailed analysis of algebraic content knowledge and pedagogical knowledge of the participants.

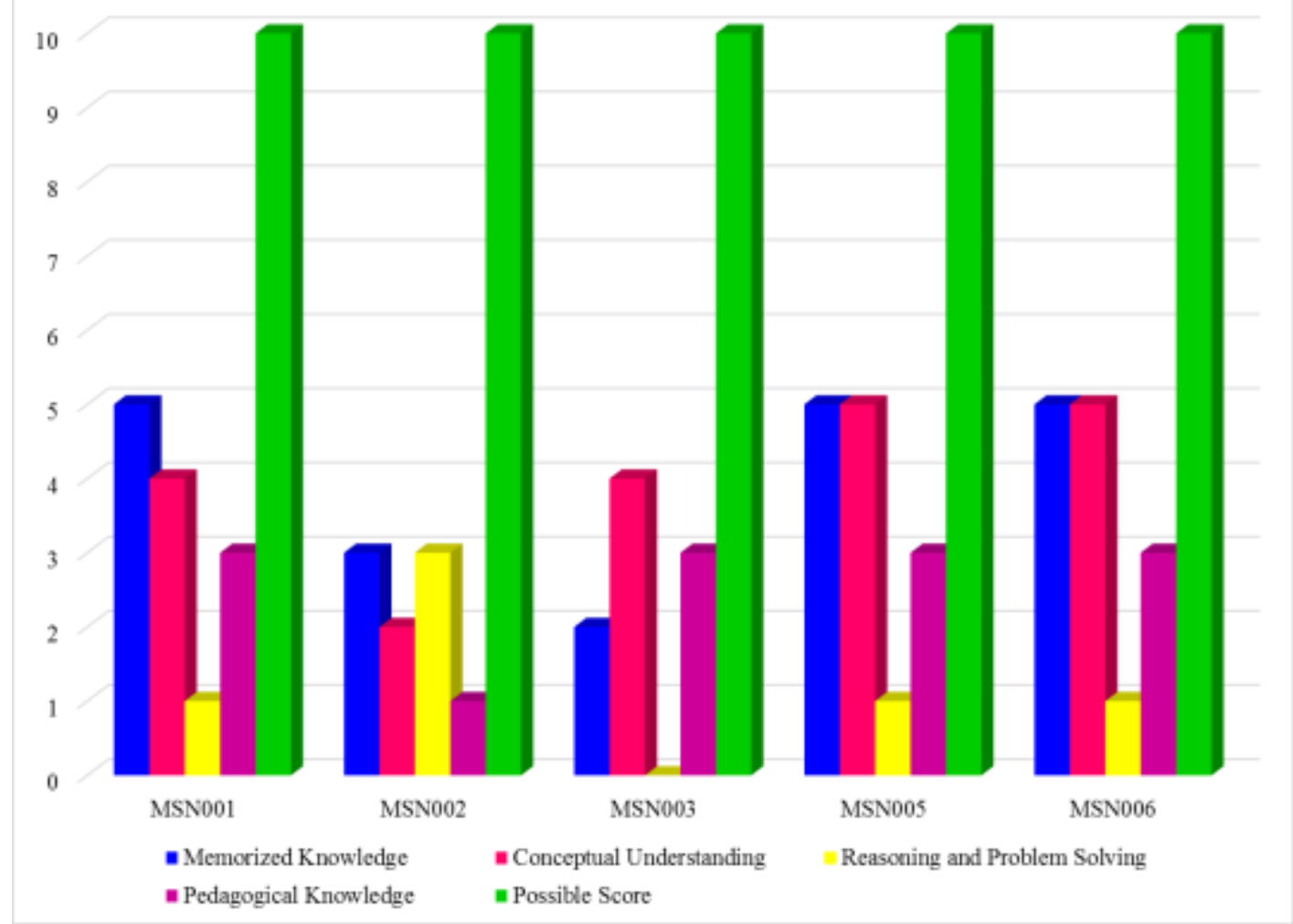

Figure 2:- In-depth analysis of algebraic content and pedagogical knowledge.

DTAMS results also showed that teachers lacked the pedagogical knowledge required to teach algebra. The highest score that was three out of a possible 10 points was obtained by four of the five participants while the remaining participant scored only one point out of 10 .

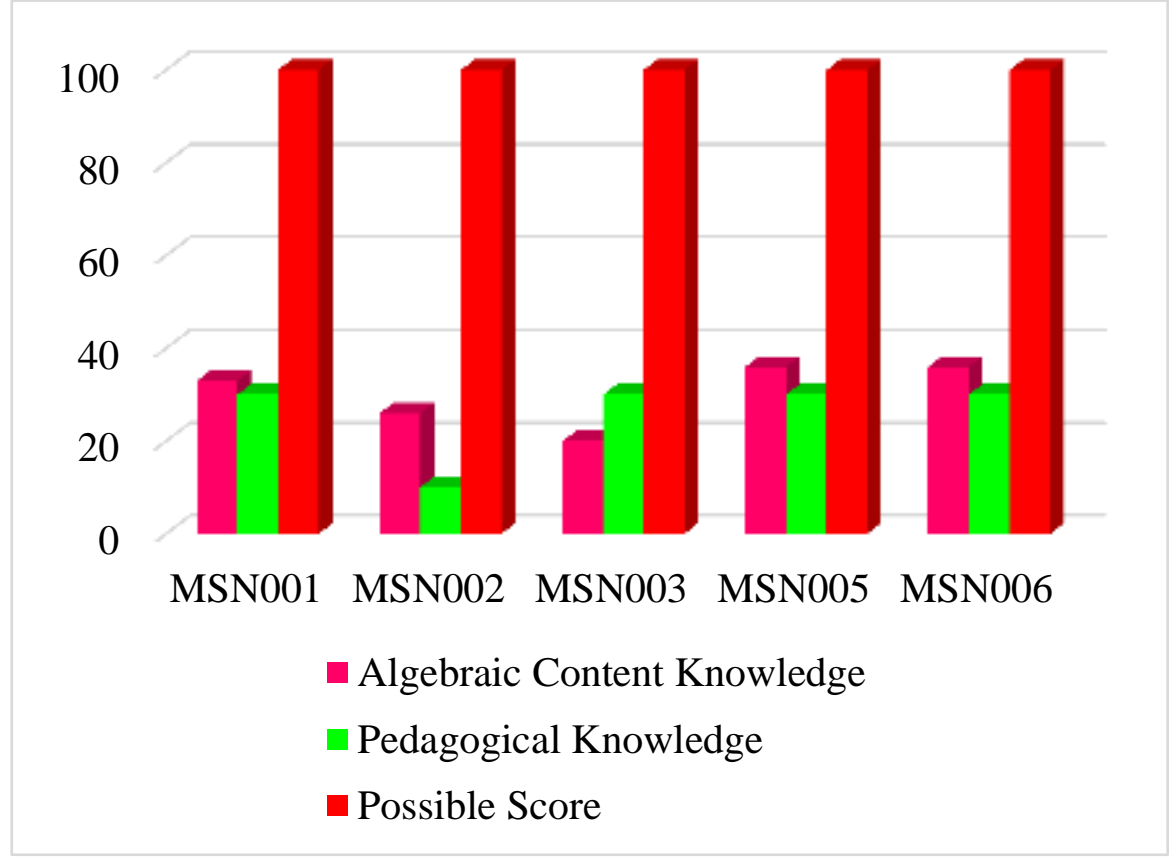

Figure 3:- Overall algebraic content and pedagogical knowledge. 
Figure 3 illustrates the overall algebraic content and pedagogical knowledge of the participants. The overall content knowledge of the individual participants was below 35\% while the pedagogical knowledge of the individual participants was below 30\% indicating that participants lacked algebraic content and pedagogical knowledge required to teach algebra at sixth grade. Moreover, it was observed that the experience of the participants did not have any impact on these results. The score expectation for a well-qualified teacher to teach sixth grade algebra is $100 \%$ as DTAMS is based on the content of middle school algebra. In other words, DTAMS covered the algebra content sixth grade students are expected to learn from these teachers. Therefore, these teachers are expected to score $100 \%$ from the DTAMS.

\section{Discussion:-}

This concurrent mixed methods study combined the strengths of qualitative and quantitative data to explore algebraic content and pedagogical knowledge of five Maldivian sixth grade mathematics teachers. Qualitative data were collected through lesson observations, analysis of algebra lesson plans and lesson notes, and interviews whereas quantitative data were collected using DTAMS. The results of qualitative data and quantitative data were consistent. From the lesson observations, analysis of lesson plans and lesson notes, interviews, and the results from DTAMS indicated that teachers lacked algebraic content and pedagogical knowledge required to teach algebra.

For example, from the observations it became clear that teachers only asked questions of the type given in the textbook, which only required memorized knowledge. None of the teachers asked any questions that required criticalthinking, creativity, or problem-solving skills. DTAMS results showed that teachers scored the lowest in questions that required reasoning and problem-solving. The highest score that was three was obtained by only one of the teachers while three of the teachers scored one and one of the teachers scored a zero out of a possible 10 points.

From the observations and the interviews it became clear that teachers lacked pedagogical knowledge and this was confirmed by DTAMS results. Four of the five teachers scored three while the remaining teacher scored a one out of a possible 10 points allocated for pedagogical knowledge. It was also observed that teachers focused on computational procedures rather than conceptual understanding. Moreover, teachers were unable to detect students' misconceptions. All these indicated the teachers not only lacked pedagogical knowledge but also conceptual understanding that was later shown by the results from DTAMS. DTAMS showed that teachers lacked conceptual understanding. Only two of the five teachers scored five points, two scored four points, and the remaining teacher scored a two out of a possible 10 points. Conceptual understanding is an important aspect of content knowledge. Lack of content knowledge limited what students were exposed to in terms of the mathematical content they were taught (Ojose, 2014; Strand \& Mills, 2014).

In summary, results obtained from qualitative data and quantitative data collected proved that teachers lacked algebraic content and pedagogical knowledge, although they believed that they had sufficient knowledge to teach algebra at sixth grade. The teachers' perception of their algebraic content and pedagogical knowledge was based on their ability to work out all the problems in the sixth grade mathematics textbook. Researchers and mathematics educators agreed that this was faulty thinking as being able to solve problems given in a textbook did not attest to having sufficient knowledge and skills required to teach the content (E. Ashworth, J. K. Corkett, R. R. Perez, E. V. Chua, personal communication, March 7, 2016; I. Hassan, personal communication, March 9, 2016; A. Shareef, personal communication, March 10, 2016). All five teachers believed that their lessons were very good and that they did not need any help. Moreover, they stated that they did not intend bring any changes to their lessons. Example of responses received from the teachers when they were asked whether they would bring any changes to the lessons if they were to reteach the lesson include:

- "No. I will teach it this way. I have been teaching this lesson this way and students understand. So no point in changing it."

- "No changes. Because this is the best way to teach for my students."

- "No changes. Because students understood the lesson. [How do you know that?] They did not ask any questions."

- "No change. Because more than $90 \%$ understood the lesson. I think."

- "No changes. I have been teaching it this way and students always understand." 


\section{Conclusion:-}

This study aimed to examine the algebraic content and pedagogical knowledge of five sixth grade mathematics teachers in the Maldives using a concurrent mixed methods multi case study approach. The main reason for selecting a mixed methods approach was to gain an in-depth understanding of the problem under study. Mixed methods research is found to complement the results obtained through either quantitative or qualitative approach only, making the results more meaningful in terms of what could be done in future to address the issue studied.

Fourteen sixth grade algebra teachers employed in the selected schools were eligible to take part in the study. These 14 teachers were approached and the seven teachers who consented to take part in the study were selected. However, two of the teachers withdrew after the first observation. Therefore, only five continued through the end of the study. As this is an in-depth study, a study of a few cases would suffice. All data collected were kept confidential to prevent the participants from any harm or negative impact that may come due to the findings of the study. Qualitative data were collected through observations of algebra lessons, analysis of algebra lesson plans and lesson notes, and interviews with the sixth grade algebra teachers while quantitative data were collected using DTAMS.

Content of the qualitative data collected was analyzed for themes and patterns while quantitative data were sent to CRMSTD staff for a detailed analysis of the algebraic content and pedagogical knolwege of the sixth grade mathematics teachers in the Maldives. Both qualitatve findings and quantitative findings were in agreement. Analysis of both qualitative and quantitative data showed that teachers lacked algebraic content and pedagogical knowledge necessary to teach algebra at sixth grade although the teacher-participants believed that they had sufficient knowledge to teach sixth grade algebra.

In short, there was no relationship between teachers' perceptions of their mastery of algebraic content and pedagogical knowledge and what teachers knew relative to algebraic content and pedagogy as measured by DTAMS. Also, as meaured by DTAMS, there were no specific algebraic content and pedagogical knowledge strengths of the sixth grade mathematics teachers with respect to their algebraic content and pedagogical knowledge. However, identified weaknesses included emphasis on memorized knowledge, lack of conceptual understanding, lack of reasoning and problem-solving, and lack of pedagogical knolwedge required to teach agebra.

\section{References:-}

1. Adam, A. \& Naseer, A. (2002). Mathematics for Maldivian Schools Six. Maldives: Educational Development Centre.

2. Adam, A. \& Naseer, A. (2002). Mathematics for Maldivian Schools Six Workbook. Maldives: Educational Development Centre.

3. Adam, A. \& Naseer, A. (2003). Mathematics for Maldivian Schools Six Teacher's Resource Book. Maldives: Educational Development Centre.

4. Baker, S. E., \& Edwards, R. (2015). How many qualitative interviews is enough?: Expert voices and early career reflections on sampling and cases in qualitative research. United Kingdom: National Centre for Research Methods \& Economic and Social Research Council. Retrieved from http://eprints.ncrm.ac.uk/2273/4/how_many_interviews.pdf

5. Ball, D. L., Lubienski, S. T., \& Mewborn, D. S. (2001). Research on teaching mathematics: The unsolved problem of teachers' mathematical knowledge. Handbook of Research on Teaching, 4, 433-456.

6. Ball, D. L., Thames, M. H., \& Phelps, G. (2008) Content knowledge for teaching: What makes it special? Journal of Teacher Education, 59(5), 389-407.

7. Begle, E. G. (1979). Critical variables in mathematics education: Findings from a survey of the empirical literature. Washington, DC: Mathematical Association of America and National Council of Teachers of Mathematics.

8. Brown, I. A., Davis, T. J., \&Kulum, G. (2011). Pre-service teachers' knowledge for teaching algebra for equity in the middle grades: A preliminary report. Journal of Negro Education, 80(3), 266-283.

9. Browning, C., Thanheiser, E., Edson, A. J., Kimani, P., Olanoff, D., Tobias, J., \& Whitacre, I. (2014). Prospective Elementary Teacher Mathematics Content Knowledge: An Introduction. Mathematics Enthusiast, 11(2), 203-216.

10. Buschang, R. E., Chung, G. K., Delacruz, G. C., \& Baker, E. L. (2012). Validating measures of algebra teacher subject matter knowledge and pedagogical content knowledge. Educational Assessments, 17(1), 1-21.

11. Caruth, G. D. (2013). Demystifying mixed methods research design: A review of the literature. Online 
Submission, 3(2), 112-122.

12. Charmaz, K. (2006). Constructing grounded theory: A practical guide through qualitative analysis. London, United Kingdom: SAGE Publications.

13. Chick, H. L., Pham, T., \& Baker, M. K. (2006). Probing teachers' pedagogical content knowledge: Lessons from the case of the subtraction algorithm. Identities, Cultures and Learning Spaces, 139-146.

14. Cheng-Yao, L., Yi-Yin, K., \& Yu-Chun, K. (2014). Changes in pre-service teachers' algebraic misconceptions by using computer-assisted instruction. International Journal for Technology in Mathematics Education, 21(3), 21-30.

15. Creswell, J. W. (2012). Educational research: Planning, conducting, and evaluating quantitative and qualitative research (Laureate custom ed.). Boston, MA: Pearson Education.

16. Darling-Hammond, L., \& Sykes, G. (2003). Wanted, A national teacher supply policy for education: The right way to meet the" highly qualified teacher" challenge. Educational Policy Analysis Archives, 11(33).

17. Diagnostic Teacher Assessments in Mathematics and Science - Middle Mathematics Teacher Assessments. (n.d.). Retrieved June 20, 2015, from http://louisville.edu/education/centers/crmstd/diag-math-assess-middle

18. El Mouhayar, R. R., \& Jurdak, M. E. (2013). Teachers' ability to identify and explain students' actions in near and far figural pattern generalization tasks. Educational Studies in Mathematics, 82(3), 379-396.

19. Fernandez, C. (2014). Knowledge base for teaching and pedagogical content knowledge (PCK): Some useful models and implications for teachers' training. Problems of Education in the 21 st Century, 60, 79-100.

20. Guest, G., Bunce, A., \& Johnson, L. (2006). How many interviews are enough? An experiment with data saturation and variability. Field methods, 18(1), 59-82.

21. Hauk, S., Toney, A., Jackson, B., Nair, R., \& Tsay, J. J. (2014). Developing a model of pedagogical content knowledge for secondary and post-secondary mathematics instruction. Dialogic Pedagogy: An International Online Journal, 2.

22. Hill, H. C., Ball, D. L., \& Schilling, S. G. (2008). Unpacking pedagogical content knowledge: Conceptualizing and measuring teachers' topic-specific knowledge of students. Journal for Research in Mathematics Education, $372-400$.

23. Jing-Jing, H. U. (2014). A critical review of Pedagogical Content Knowledge components: nature, principle and trend. International Journal of Education and Research, 2(4), 411-424.

24. Kleickmann, T., Richter, D., Kunter, M., Elsner, J., Besser, M., Krauss, S., ... \& Baumert, J. (2015). Content knowledge and pedagogical content knowledge in Taiwanese and German mathematics teachers. Teaching and Teacher Education, 46, 115-126.

25. Koency, G., \& Swanson, J. (2000). The special case of mathematics: Insufficient content knowledge a major obstacle to reform.

26. Lange, K., Kleickmann, T., \& Moller, K. (2012). Elementary teachers' pedagogical content and student achievement in science education. In C. Bruguiere, A. Tiberghien \& P. Clement (Eds.), Science Learning and Citizenship. Proceedings of the Ninth ESERA-Conference 2011. Lyon.

27. Liu, S. (2010). Teachers' knowledge: Review from comparative perspective. New Horizons in Education, 58(1), 148-158.

28. Lopez-Fernandez, O., \& Molina-Azorin, J. F. (2011). The use of mixed methods research in interdisciplinary educational journals. International Journal of Multiple Research Approaches, 5(2), 269-283.

29. Ma, L. (1999). Knowing and teaching elementary mathematics: Teachers' understanding of fundamental mathematics in China and the United States. Mahwah, NJ: Lawrence Erlbaum Associates.

30. Marshall, B., Cardon, P., Poddar, A., \& Fontenot, R. (2013). Does sample size matter in qualitative research?: A review of qualitative interviews in IS research. Journal of Computer Information Systems, 54(1), 11-22.

31. Mason, M. (2010, August). Sample size and saturation in PhD studies using qualitative interviews. In Forum Qualitative Sozialforschung/Forum: Qualitative Social Research (Vol. 11, No. 3).

32. Miles, M. B., \& Huberman, A. M. (1994). Qualitative data analysis: An expanded sourcebook. London: Sage Publications.

33. Naseer, M. S. (2015, September). Analysis of students' errors and misconceptions in pre-university mathematics courses. In M. N. Salleh, \& N. F. Z. Abedin, (Eds.), Proceedings: First International Conference on Teaching \& Learning 2015 (p. 34-39). Langkawi, Malaysia: MNNF Publisher. ISBN 978-967-13637-1-3.

34. National Institute of Education. (2014). Mathematics in the National Curriculum Key Stage 2 (Grades 4, 5, \& 6). Maldives: National Institute of Education.

35. Ojose, B. (2014). Teaching Certain Mathematical Axioms: The Role Played by Conceptual Knowledge of Algebra Teachers. National Teacher Education Journal, 7(1).

36. Patton, M. Q. (2002). Qualitative research and evaluation methods (3rd ed.). London: Sage. 
37. Piccolo, D. (2008). Views of content and pedagogical knowledges for teaching mathematics. School Science and Mathematics, 108(2), 46-48.

38. Rittle-Johnson, B., Matthews, P. G., Taylor, R. S., \& McEldoon, K. L. (2011). Assessing knowledge of mathematical equivalence: A construct-modeling approach. Journal of Educational Psychology, 103(1), 85-104.

39. Ross, A., \& Onwuegbuzie, A. J. (2012). Prevalence of mixed methods research in mathematics education. The Mathematics Educator, 22(1), 84-113.

40. Russell, M., O’Dwyer, L. M., \& Miranda, H. (2009). Diagnosing students' misconceptions in algebra: Results from an experimental pilot study. Behavior research methods, 41(2), 414-424.

41. Saderholm, J., Ronau, R., Brown, E. T., \& Collins, G. (2010). Validation of the diagnostic teacher Assessments of mathematics and science (DTAMS) instrument. School Science and Mathematics, 110(4), 180-192.

42. Schnepper, L. C., \& McCoy, L. P. (2013). Analysis of Misconceptions in High School Mathematics. Networks, 15(1).

43. Shirvani, H. (2015). Pre-service Elementary Teachers' Mathematical content Knowledge: A Predictor of Sixth Graders' Mathematics Performance. International Journal of Instruction, 8(1), 133-142.

44. Shulman, L. S. (1986). Those who understand: Knowledge growth in teaching. Educational Researcher, 15(2), 4-14. Retrieved from https://www.math.ksu.edu/ bennett/onlinehw/qcenter/shulmanpck86.pdf

45. Shulman, L. S. (1987). Knowledge and teaching: Foundations of the new reform. Harvard Educational Review, 57(1), 1-23.

46. Stoddart, T., Connell, M., Stofflett, R., \& Peck, D. (1993). Reconstructing elementary teacher candidates' understanding of mathematics and science content. Teaching and Teacher Education, 9(3), 229-241.

47. Strand, K., \& Mills, B. (2014). Mathematical Content Knowledge for Teaching Elementary Mathematics: A Focus on Algebra. The Mathematics Enthusiast, 11(2), 385-432.

48. Tajudin, N. M. (2014). Exploring prospective mathematics teachers' mathematical knowledge for teaching algebraic problem-solving. Proceeding of the Social Sciences Research ICSSR 2014 (e-ISBN 978-967-11768-70). Malaysia: Kota Kinabalu, Sabah.

49. Taton, J. A. (2015). Much more than it's cooked-up to be: Reflections on doing math and teachers' professional learning. Perspectives on Urban Education, 12(1).

50. Tennant, G., \& Colloff, K. (2014). Fruit salad algebra: Alive and kicking!. Mathematics Teaching, (239), 40-43.

51. Thanheiser, E., Browning, C., Edson, A., Lo, J. J., Whitacre, I., Olanoff, D., \& Morton, C. (2014). Prospective elementary mathematics teacher content knowledge: What do we know, what do we not know, and where do we go?. The Mathematics Enthusiast, 11(2), 433-448.

52. United Nations Children's Fund (UNICEF) \& National Institute of Education (NIE). (2014). Longitudinal study on the impact of curriculum reforms 2012-2013. Maldives: UNICEF Maldives Country Office.

53. Venkatesh, V., Brown, S. A., \& Bala, H. (2013). Bridging the qualitative-quantitative divide: Guidelines for conducting mixed methods research in information systems. MIS quarterly, 37(1), 21-54.

54. Welder, R. M. (2012). Improving algebra preparation: Implications from research on student misconceptions and difficulties. School Science and Mathematics, 112(4), 255-264. 